\section{Metabolic diseases}

\section{G226 WHAT IS THE SIGNIFICANCE OF A RAISED PHENYLALANINE IN NEONATAL SCREENING?}

M. Galogavrou', M. Downing'2, R.J. Pollitt', J.R. Bonham²,M.J. Sharrard'. Departments of Paediatrics' and Chemical Pathology and Neonatal Screening ${ }^{2}$, Sheffield Children's Hospital

Infants born in UK are screened for phenylketonuria (PKU) on day 6. False positive results are inevitably generated by screening programmes; in PKU screening, galactosaemia may be a cause of elevated phenylalanine (phe), but the clinical significance in others is unknown.

Aim: to examine the outcome of non-PKU infants with a raised phe on neonatal screening, and to determine the incidence of raised phe in galactosaemia.

Method: (1) All infants born and screened in Trent between $1 / 10 / 99$ and $30 / 09 / 01$ were included. Those with persistently raised phe were followed by enquiry, and galactose measured in the screening blood spot. (2) Infants born in Trent between 1/10/94 and $30 / 9 / 01$ with galactosaemia were included. Reference was made back to the neonatal phe level.

Results: Between 1/10/99 and 30/09/01, 110320 neonates were screened. $67 \mathrm{had}$ an elevated phe (>150:mol/L). Of these, 43 had phe in the range $150-200: \mathrm{mol} / \mathrm{L}$, with a normal amino acid profile and no galactose present. Galactosaemia was subsequently diagnosed on clinical grounds in one, but full feeding had not been established. 14 neonates had an initial phe in the range 200-400:mol/L; 12 had normalised by day 27 , one had atypical PKU and one had mild deranged liver function test for which no cause was found. 10 neonates had an initial phe of $>400: \mathrm{mol} / \mathrm{L}$; eight of these had confirmed PKU and two had galactose detected, galactosaemia being subsequently confirmed. Between 1/10/94 and 30/9/ 01, 420,000 neonates were screened for PKU and 11 babies with galactosaemia were born in Trent. Seven were diagnosed on PKU screening: one was clinically diagnosed (but would have been so on screening), one was not detected but was prospectively treated, one was not detected but was not on full feeds and one was not detected on screening.

Conclusions: Raised phe on neonatal screening is rarely encountered outside PKU (typical or atypical), and is most frequently caused by galactosaemia. Most galactosaemia cases are diagnosed as a result of PKU screening. Other forms of neonatal liver disease very rarely elevate phe.

\section{G227 PHENYLKETONURIA: COMPLIANCE WITH CURRENT RECOMMENDATIONS}

M. Schmidt ${ }^{4}$, F.J. White', S.K. Hall ${ }^{2}$, A. MacDonald ${ }^{2}$, G. Rylance ${ }^{2}$, A. Boneh $^{3}$, D.E. Francis ${ }^{3}$, G.J. Shortland', A. Vail ${ }^{5}$, J.H. Walter'. 'Royal Manchester Children's Hospital, UK; ${ }^{2}$ Birmingham Children's Hospital, UK; ${ }^{3}$ Royal Melbourne Children's Hospital, Australia; ${ }^{4}$ University Hospital of Wales, Cardiff; ${ }^{5}$ Biostatistics Group, University of Manchester

Blood phenylalanine (phe) concentration in infancy and childhood is the major determinant of cognitive outcome in phenylketonuia (PKU). Published guidelines for the management of

PKU give recommendations at different ages for desirable blood concentrations and for the frequency of monitoring. In order to determine how achievable these are we have audited the results of patients from 4 PKU clinics for 1994-2000.

Data, available from 330 patients under $20 \mathrm{yr}$ of age, were analysed in four age groups and compared with each clinic's own recommendations. Results are given as median with the interquartile range (IQR). The frequency of blood sampling is expressed as a percentage of that recommended for each age group. Samples with phe concentrations above the upper recommended level are expressed as a percentage of all samples taken. These results indicate the difficulty in maintaining biochemical control in PKU, especially in older children, and serve as a benchmark for the quality of control that can be realised in practice.

\begin{tabular}{|c|c|c|}
\hline \multicolumn{3}{|c|}{ Abstract G227 } \\
\hline & \multicolumn{2}{|c|}{ Mean phe levels $(\mu \mathrm{mol} / \mathrm{I})$} \\
\hline & Median & IQR \\
\hline $0-4 \mathrm{yr}$ & 337 & 287-392 \\
\hline $5-9 \mathrm{yr}$ & 400 & $340-507$ \\
\hline $10-14 \mathrm{yr}$ & 577 & $464-793$ \\
\hline \multirow[t]{3}{*}{$15-19 \mathrm{yr}$} & 893 & $660-1116$ \\
\hline & \multicolumn{2}{|c|}{ Frequency of blood sampling (\%) } \\
\hline & Median & IQR \\
\hline $0-4 \mathrm{yr}$ & 81 & $63-90$ \\
\hline $5-9 \mathrm{yr}$ & 86 & $58-113$ \\
\hline $10-14 \mathrm{yr}$ & 71 & $50-94$ \\
\hline \multirow[t]{3}{*}{$15-19 \mathrm{yr}$} & 46 & $25-75$ \\
\hline & \multicolumn{2}{|c|}{ Samples > recommended phe (\%) } \\
\hline & Median & IQR \\
\hline $0-4 \mathrm{yr}$ & 28 & $18-45$ \\
\hline $5-9 \mathrm{yr}$ & 27 & $11-48$ \\
\hline $10-14 \mathrm{yr}$ & 50 & $26-79$ \\
\hline $15-19$ yr & 79 & $33-96$ \\
\hline
\end{tabular}

\section{G228 DIAGNOSING FAT OXIDATION DEFECTS IN THE PRESENCE OF KETONURIA}

E. Wraige', M.P. Champion', C. Turner', R.N. Dalton'2. 'Department of Paediatric Metabolic Medicine, ${ }^{2}$ Nationwide Kidney Research Unit, Guy's Hospital, London

Aims: To demonstrate that the presence of ketonuria does not exclude a diagnosis of a fat oxidation defect and to illustrate the value of acylcarnitine analysis in the diagnosis of these disorders.

Background: Initial evaluation of a child with hypoglycaemic encephalopathy includes urinalysis for ketones. Presence of ketones is conventionally thought to exclude inherited fat oxidation disorders. It is now recognised that in medium chain acyl-CoA dehydrogenase deficiency ketonuria may accompany hypoglycaemia. Ketonuria at presentation has not previously been described in very long chain acyl-coA dehydrogenase deficiency (VLCADD).

Case report: We describe a two year old child who presented with an encephalopathic illness and was found to be hypoglycaemic (glucose $1.7 \mathrm{mmol} / \mathrm{l}$ ). Urine organic acid analysis revealed massive ketonuria. However, acylcarnitine was informative demonstrating a significant elevation of tetradecanoylcarnitine which suggested a diagnosis of VLCADD. This diagnosis was subsequently confirmed on the basis of enzyme activity and genotype.

Discussion: Urinary organic acid analysis has been the established method for investigating the child with a suspected fat oxidation defect. In the case described this was uninformative and misleading. In contrast, analysis of plasma acylcarnitines resulted in prompt diagnosis.

Conclusion: Ketonuria does not exclude a fat oxidation defect and plasma acylcarnitines should be considered a mandatory first line investigation of any child presenting with acute hypoglycaemic encephalopathy even in the presence of massive ketonuria.

\section{G229 "CYCLICAL VOMITING SYNDROME" BEWARE OF HYPOADRENALISM SECONDARY TO X LINKED ADRENOLEUKODYSTROPHY (ALD)}

P. Desai, R.N. Babu Mahesh. Paediatric Department, St John's Hospital, Wood Street, Chelmsford, CM2 9BG, UK

It is fairly common for children to present with cyclical vomiting. Before labeling them as suffering from 'Cyclical Vomiting Syndrome' (Migraine Variant) we recommend metabolic investigations to rule out hypoadrenalism and ALD. We describe two such cases.

Case 1: An 11 year old boy had seven episodes of vomiting with dehydration, requiring IV hydration each time and was being treated as 'cyclical vomiting' for 9 years. During some episodes it was noted that he had mild hyponatraemia (Nal28 and $132 \mathrm{mmol} /$ litre) and mild hypoglycaemia (Blood glucose $2.8 \mathrm{mmols}$ ). Metabolic investigations showed raised VLCFA and hypoadrenalism, which confirmed 
diagnosis of $X$ linked ALD. The patient has been started on dietary therapy with Lorenzo's oil and replacement steroids, has no neurological problems, with normal MRI, nerve conduction and neuropsychological testing. 2 years post diagnosis on treatment.

Case 2: A 5 year old boy had 3 episodes of protracted vomiting, dehydration and lethargy. The child was managed as 'Cyclical Vomiting Syndrome' for 3years. During $1^{\text {st }}$ and last admission he had hypoglycaemia (BM $2.8 \mathrm{mmols}$ ), mildly raised liver enzymes, mild hyponatraemia ( $\mathrm{Na} 131 \mathrm{mmols} / \mathrm{L})$. Metabolic investigations showed raised VLCFA. Addison's disease was proven by Synacthen test. X linked ALD was established. He was started on Lorenzo's oil and replacement steroids. Despite 6 months treatment the VEP and MRI showed deterioration. Hence a BMT was carried out 18 months ago.

ALD is an $X$ linked disease (gene defect at $X q 28$ ) in which there is a deficiency of peroxisomal enzyme lignoceroyl-CoA Ligase, leading to failed degradation and hence accumulation of VLCFA. The importance of early diagnosis of ALD is two folds. Firstly as highlighted in case one, dietary therapy with Lorenzo's oil before onset of neurological symptoms (Addisonian presentation often precedes neurological disease) prevents neurological deterioration, the treatment for early neurological disease being BMT, as in case 2 . Secondly family members can be screened for early detection. These cases demonstrate the importance of careful evaluation of patients with repeated episodes of protracted vomiting presenting to paediatric practice.

\section{G230 LYSINURIC PROTEIN INTOLERANCE MASQUERADING AS A UREA CYCLE DISORDER}

S.J. Heap, J.R. Bonham, M.J. Sharrard. Department of Chemical Pathology and Neonatal Screening, and Department of Paediatrics Sheffield Children's Hospital, Western Bank, Sheffield
Lysinuric protein intolerance (LPI) is an autosomal recessive disorder of cationic amino acid transport that causes disruption of the urea cycle and non-specific multi-system dysfunction.

$\mathrm{IH}$, a 14 month-old non-identical twin girl, healthy at birth, presented to a local DGH with vomiting and lethargy. Her weight was $<0.4$ th centile and she had mild developmental delay with a history of diarrhoea, vomiting and recurrent chest infections. Routine investigations showed mild hyperammonaemia (104 micromol/L). Further investigations revealed marked elevation of urinary orotic acid and uracil, elevated plasma glutamine and low ornithine suggestive of a urea cycle disorder. Urine amino acids indicated a diagnosis of LPIrenal tubular reabsorption of lysine $<5 \%$ (normal 95.6-100\%). Nitrogen excretion improved with protein restriction, sodium benzoate and citrulline. Carnitine, vitamin and mineral supplements were prescribed. Plasma ammonia normalised and urinary amino/organic acid markers showed improvement. Investigation of $\mathrm{IH}^{\prime} \mathrm{s}$ twin, with similar symptoms, was also found to have LPI-she had had a normal sweat test at 4 months, but no diagnosis made. 2 months later, both twins showed marked weight gain and clinical improvement, but evidence of osteoporosis and mild hepatomegaly. Referral has been made for immunological and haematological investigation, abnormalities of which are frequently reported in this rare disorder. Many features of LPI are similar to those of protein calorie malnutrition as a consequence of lysine deficiency - lysine is integral to most proteins, and particularly collagen. The case highlights the need for basic metabolic investigations (organic acids, plasma/urine amino acids, plasma ammonia) for investigation of recurrent vomiting and diarrhoea, failure to thrive and repeated infection, after the exclusion of common causes. This practice would exclude many inborn errors at an early stage, reducing the long-term damage of delayed diagnosis, for example, developmental delay secondary to prolonged hyperammonaemia. 